\title{
Applicability Research of Drought Monitoring Indexes on Mongolia Plateau Based on the EOS/MODIS Time Sequence
}

\author{
Duwala $^{1}$, Yushan $^{2}$, Narisu $^{1}$, Guixiang Liu ${ }^{3, *}$ \\ ${ }^{1}$ Inner Mongolia Autonomous Region Ecological and Agricultural Meteorology Center, Inner \\ Mongolia Huhhot 010051, China \\ ${ }^{2}$ Inner Mongolia Autonomous Region Key Laboratory of RS \& GIS, Inner Mongolia Huhhot 010022, \\ China \\ ${ }^{3}$ Grassland Research Institute of Chinese Academy of Agricultural Sciences, hohhot 010010, China

\section{基于 EOS/MODIS 时间序列的不同干旱指数在 蒙古高原的适用性研究} \\ 都瓦拉 ${ }^{1}$, 玉山 ${ }^{2}$, 娜日苏 ${ }^{1}$, 刘桂香 ${ }^{3, *}$ \\ ${ }^{1}$ 内蒙古自治区生态与农业气象中心, 内蒙古呼和浩特 010051 , 中国 \\ 2 内蒙古自治区遥感与地理信息系统重点实验室, 内蒙古呼和浩特 010022 , 中国 \\ ${ }^{3}$ 中国农业科学院草原研究所, 呼和浩特 010010 , 中国
}

\begin{abstract}
Taking Mongolia plateau as a study area, make use of the temperature and vegetation products of the EOS/MODIS data to calculate four index they are vegetation condition index $(\mathrm{VCI})$ and temperature condition index (TCI) and vegetation health index (VHI) and vegetation supply water index (VSWI). Mapped the Mongolia plateau for 2003-2013 growing season (from May to September) time and space distribution of drought. SPSS software is used to analyze the various index and the correlation between the soil moisture measured data, so as to choose the most suitable for remote sensing monitoring index of drought Mongolia plateau. The results showed: VHI and VSWI index relative to other two indexes is applicable to the Mongolian plateau drought monitoring.
\end{abstract}

Keywords: Remote sensing; Drought monitoring; Correlation analysis; Mongolian

*通讯作者: 刘桂香, Email: liugx804@163.com
Plateau; EOS/MODIS time sequence

\section{摘要}

以蒙古高原为研究区, 利用了美国国家航空航 天局 (NASA) 研究生产的蒙古高原研究区范 围内的 2003 2013 年生长季 (每年 5 9 月) 的 132 景 MYD13C2 和 MYD11C3 数据计算了 植被条件指数 $(\mathrm{VCI})$ 、条件温度指数 $(\mathrm{TCI})$ 、 植被健康指数 (VHI) 和植被供水指数 (VSWI) 等四个指数的干旱的时空分布情况, 监测结果 与 $10 \mathrm{~cm}$ 土壤相对湿度数据进行相关性分析, 从而选择最适用于蒙古高原的旱情遥感监测 的指数。结果表明, VCI、TCI、VHI, VSWI 四个指数与 $10 \mathrm{~cm}$ 土壤相对湿度的相关系数均 以通过了 0.01 的显著性检验。其中, VHI 与 VSWI 两个指数在时空上都有较好的较稳定。 关键词: 遥感; 干旱监测; 相关性分析; 蒙古 高原; EOS/MODIS 时间序列

1. 引言

20 世纪以来, 全球变暖加剧, 旱灾发生范围 扩大, 发生频率增加, 防灾减灾及灾害评估工 
作得到各国政府前所未有的重视。中国北方草 原地处东亚季风气候和中亚内陆气候边缘地 带, 是气候敏感区。干旱具有连年长, 频率高 的特点, 是农牧业发展的主要制约因素。蒙古 国处于我国上风上水地区, 是我国重要的生 态环境屏障。其生态系统状态及其变化对于中 国华北乃至整个东北亚地区的环境有着重要 影响。对其干旱灾害的监测与评价研究有益于 减小我国资源环境风险系数, 实现共同发展 [1]。20世纪90年代与60年代相比蒙古高原温度 上升速率远高于世界平均 $0.6^{\circ} \mathrm{C}$ 的水平 $[1]$ 。全 球变暖会导致地表蒸发的增加, 从而引发干旱 化的发展和加剧[2]。蒙古高原干旱、半干旱区 问题将变得更为严重[3]。但目前以蒙古高原为 研究区的旱情监测研究非常少。

在区域尺度的干旱监测中遥感具有快速、 实时、动态以及获取信息具有可比性等特点。 因此, 利用遥感对蒙古高原进行宏观大尺度上 的旱情监测研究具有理论和实践上的重要意 义。干旱遥感监测方法有光学遥感和微波遥感。 基于光学遥感的干旱监测研究较为成熟, 各类 指数较多。但是由于干旱的发生发展是气候背 景和区域地气相互作用的产物, 因此, 在不同 的区域各类指数在不同区域的适用性都各不 相同。因此, 为了保证干旱监测结果的准确性, 非常有必要进行各类指数在蒙古高原干旱监 测中的适应性研究。本文以蒙古高原为研究区, 选择EOS/MODIS数据的温度和植被产品计算 了植被条件指数 $(\mathrm{VCI})$ 、条件温度指数 $(\mathrm{TCI})$ 、 植被健康指数 (VHI) 和植被供水指数 (VSWI) 等四个指数与实测土壤湿度之间的进行了分 析, 对四个指数在蒙古高原干旱监测中的作用 进行了综合评价。

\section{2. 材料和方法}

\section{1. 研究区概况}

蒙古高原大致包括了蒙古国全部地区，俄罗斯 联邦西伯利亚部分地区, 以及中国内蒙古自治 区和新疆维吾尔自治区的部分地区。本文的研 究区域位于 $87^{\circ} 50^{\prime} \sim 126^{\circ} 15^{\prime} \mathrm{N}$, $37^{\circ} 17 \sim 53^{\circ} 22 \mathrm{E}$, 面积约 272 万 $\mathrm{km} 2$, 包括蒙 古国全境和中国内蒙古自治区, 是蒙古高原的 主体部分（如图 1)。蒙古高原宏观地貌主要 为山地和高平原, 是典型的大陆性气候区; 气
候特点为冬季严寒漫长, 夏季炎热短暂, 降水 稀少; 除高原东部、东南部以及北部等少数地 区外, 蒙古高原绝大部分地区年降水量均少于 $400 \mathrm{~mm}$ 。



图 1. 研究区区位图

\section{2. 数据}

利用了美国国家航空航天局（NASA）研究生 产的蒙古高原研究区范围内的 2003 2013 年 生长季 (每年 5 9 月) 的 132 景 MYD13C2 和 MYD $11 \mathrm{C} 3$ 数据。实测土壤数据是研究区内 的与遥感数据同期的 $10 \mathrm{~cm}$ 土壤相对湿度数 据。

\section{3. 研究方法}

本文选择 EOS/MODIS 数据的温度和植被产品 计算了植被条件指数 ( VCI)、条件温度指数 ( TCI)、植被健康指数（VHI）和植被供水指 数（VSWI）等四个指数的蒙古高原干旱的时 空分布情况。应用相关分析法分析各指数与土 壤湿度实测数据间的相关关系, 从而选择最适 用于蒙古高原的旱情遥感监测的指数。

\section{3 结果与分析}

\section{1 指数计算与干旱时空分布分析}

（1）植被条件指数

Kogan 提出植被条件指数 (vegetation condition index, VCI) 的概念。植被条件指数 （VCI）考虑了降水与植被水分相对应的情况 可以用来反映当地旱情[4]。

$$
V C I=\frac{(N D V I-N D V I m i n)}{(N D V I m a x-N D V I m i n)} \times 100
$$

式中: NDVI 为经平滑处理的特定年归一化植 
Risk Analysis and Crisis Response in Big Data Era (RAC-16)

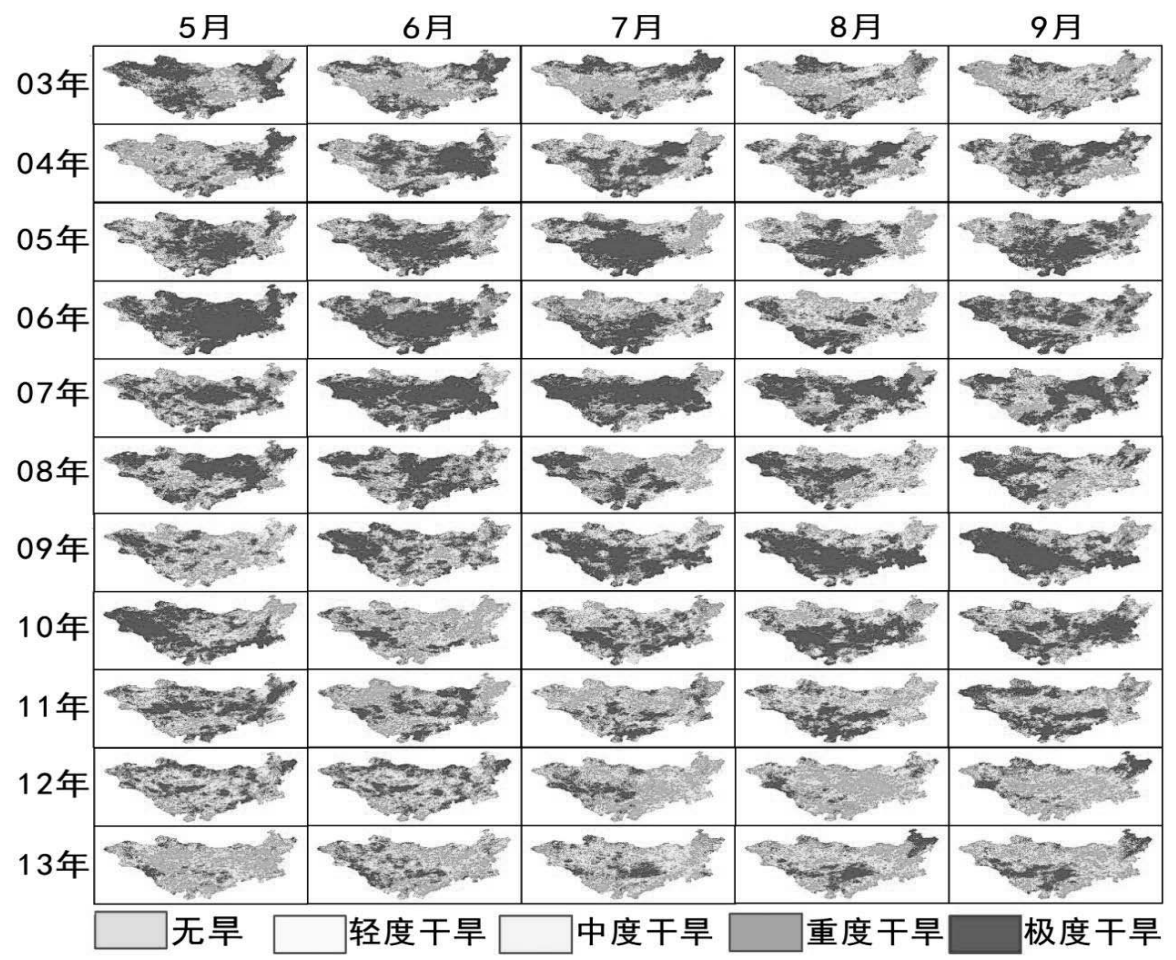

图 2. VCI 旱情监测结果

被指数, NDVImin 和 NDVImax 分别为经平滑 处理的多年绝对最小、最大归一化植被指数。

从 VCI 时间分布结果发现, 2007 年早情 发生程度是 5 年里最为严重的一年, 5-9 月都 有大范围的严重程度的干旱发生；2011、2012 和 2013 年植被生长期旱情较轻、蒙古高原区 基本没有大范围的特大干旱发生； 2003-2007 年 5-9 月旱情呈增长趋势，2003、2007-2013 年 5-9 月旱情呈减缓趋势。该监测结果与历史 旱情资料对比分析在空间分布上基本一致 (图 2)。

在生长季发生最大面积极度干旱和无早 的年份都为 2013 年, 面积分别为 402.82 和 234.375 万平方公里; 重度和中度干早面积最 大年份分别发生在 2008 年和 2010 年生长季, 面积分别为 335.8625 和 342.5725 万平方公里; 生长季发生最大面积轻度干旱的年份为 2007 年, 面积为 728.69 万平方公里。

从 VCI 空间分布结果发现：2003-2013 年生长季蒙古高原重度以上干旱主要分布于 高原中部和西部, 发生面积占研究时段的 $43.6 \%$
和 30.9\% (表 1); 中度干旱分布在高原东部和 中部区域, 发生面积占研究时段的 $21.8 \%$ 和 $18.2 \%$ 。轻度干早主要分布于高原西部区域, 发生面积占研究时段的 $47.3 \%$ 。

表 1. 03-13 年生长季干早面积占研究时段百分比 $(\%)$

\begin{tabular}{cccc}
\hline 等级 & 东部 & 中部 & 西部 \\
\hline 重度以上 & $25.5 \%$ & $43.6 \%$ & $30.9 \%$ \\
\hline 中度 & $21.8 \%$ & $18.2 \%$ & $12.7 \%$ \\
\hline 轻度 & $23.6 \%$ & $27.3 \%$ & $47.3 \%$ \\
\hline 无早 & $29.1 \%$ & $10.9 \%$ & $9.1 \%$ \\
\hline
\end{tabular}

注: 重度以上包括重度和极度两个等级。

(2) 条件温度指数

条件温度指数 TCI 强调了干旱、温度与作 物长势的关系[4]。计算公式如下:

$$
T C I=\frac{(\text { BTmax }-B T i)}{(\text { BTmax }- \text { BTmin })} \times 100
$$

式中: BTi 为某一特定年第 $\mathrm{i}$ 个时期的亮度温 度的值; BTmax 和 BTmin 分别表示所研究年 限内第 $\mathrm{i}$ 个时期亮度温度的最大值和最小值。 TCI 愈小，表示愈干旱。 
Risk Analysis and Crisis Response in Big Data Era (RAC-16)



图 3. TCI 旱情监测结果

从 TCI 时间分布结果发现: 2007 年旱情 发生程度是 5 年里最为严重的一年, 6-9 月都 有大范围的眼中程度的干旱发生, 5 月较轻; 2012 和 2013 年 5 月都有严重的旱情发生, 以 特大旱情为主, 6-9 月旱情较轻; 2000 年和 2011 年生长期旱情较轻; 全区基本没有大范围的特 大干旱发生; 2000-2007 年 6-9 月旱情增长趋 势，2007-2013 年 6-9 月旱情减缓趋势。该监 测结果与历史旱情资料对比分析在空间分布 上基本一致, 但发生旱情程度上存在差异 (图 $3)$ 。

在生长季发生最大面积极度干旱的年份 为 2003 年, 干早面积为 353.045 万平方公里; 重度和中度干旱面积最大年份都发生在 2005 年生长季, 干旱面积分别为 455.485 和 364.915 万平方公里; 轻度干旱和无旱最大面积分别发 生在 2007 年和 2013 年生长季, 面积分别为 908.75 和 126.1525 万平方公里。

从 TCI 空间分布结果发现: 2003-2013 年生长季蒙古高原重度以上干旱主要分布于 高原中部和西部, 发生面积占研究时段的 $40.0 \%$ 和 $32.7 \%$ (表 2); 中度干早分布在高原东部区
域, 发生面积占研究时段的 $16.4 \%$ 。轻度干早 主要分布于高原西部区域, 发生面积占研究时 段的 $40.0 \%$ 。

表 2. 03-13 年生长季干早面积占研究时段百分比 (\%)

\begin{tabular}{clll}
\hline 等级 & 东部 & 中部 & 西部 \\
\hline 重度以上 & $27.3 \%$ & $40.0 \%$ & $32.7 \%$ \\
\hline 中度 & $16.4 \%$ & $7.3 \%$ & $7.3 \%$ \\
\hline 轻度 & $38.2 \%$ & $34.5 \%$ & $40.0 \%$ \\
\hline 无早 & $18.2 \%$ & $18.2 \%$ & $20.0 \%$ \\
\hline
\end{tabular}

注: 重度以上包括重度和极度两个等级。

（3）植被健康指数

基于单一植被状态指数和温度条件指数 的旱情监测在时空上存在一定的差异, 通过研 究发现, 利用 TCI 和 VCI 进行线性组合而形 成的植被健康指数, 可以综合植被和地表温度 在旱情监测方面的优势, 基于此指标可以很好 的监测干旱情况[5]。计算公式如下:

$$
V H I=a \times V C I+(l-a) \times T C I
$$

式中: a 代表 VCI 的权重,而 1-a 代表 TCI 的权 重。由于不同时间,不同地区 VCI 和 TCI 对旱 情的响应情况有所差异,VCI、TCI 的贡献一般 没有确定的值,在此情况下 $\mathrm{a}$ 默认 0.5 。 


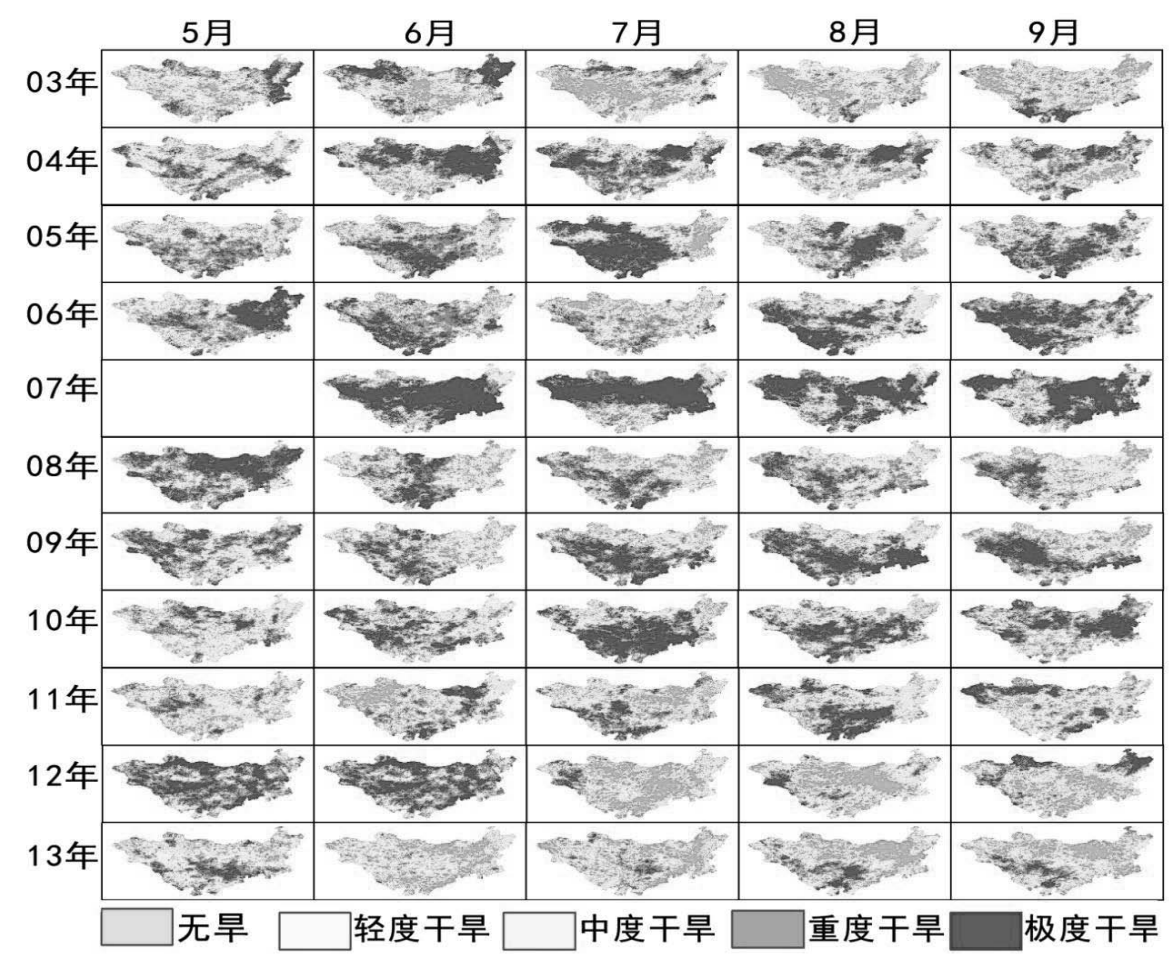

图 4. VHI 旱情监测结果

根据植被状态指数的时间分布结果发现: 蒙古高原 2003-2013 年生长期各月早情发生范 围程度基本一致, 2007 年早情发生程度最严 重且分布范围较广, 以特旱和重旱为主; 2003, 2011，2012、2013 年基本无明显大范围的特 大干旱发生。

在生长季发生最大面积极度干旱的年份 为 2012 年,干旱面积为 473.0025 万平方公里; 重度和中度干旱面积最大年份分别发生在 2008 和 2010 年生长季, 干早面积分别为 548.6925 和 484.7425 万平方公里; 轻度干旱 和无旱最大面积分别发生在 2007 年和 2013 年 生长季, 面积分别为 536.5875 和 376.7625 万 平方公里。

从 VHI 空间分布结果发现：2003-2013 年生长季蒙古高原重度以上干早主要分布于 高原中部区域, 发生面积占研究时段的 55.6\% (表 3); 中度干旱在高原各个区域都有分布。 轻度干早主要分布于高原西部区域, 发生面积 占研究时段的 $57.4 \%$ 。
表 3. 03-13 年生长季干早面积占研究时段百分比 (\%)

\begin{tabular}{clll}
\hline 等级 & 东部 & 中部 & 西部 \\
\hline 重度以上 & $29.6 \%$ & $55.6 \%$ & $16.7 \%$ \\
\hline 中度 & $27.8 \%$ & $29.6 \%$ & $20.4 \%$ \\
\hline 轻度 & $24.1 \%$ & $9.3 \%$ & $57.4 \%$ \\
\hline 无旱 & $18.5 \%$ & $5.6 \%$ & $5.6 \%$ \\
\hline
\end{tabular}

注: 重度以上包括重度和极度两个等级。

（4）植被供水指数

植被供水指数（VSWI）通过观测温度及 NDVI 值来进行旱灾监测的 [6]。植被供水指数 VSWI 来监测土壤水分的变化, 表示为:

$$
V S W I=T g / N D V I
$$

式中: $T g$ 为作物冠层温度; NDVI 为归一 化植被指数。

从植被供水指数的时间分布结果发现, 2003-2013 年全区均有不同程度的旱情发生, 年际和年内之间的旱情发生范围及旱情程度 基本一致, 而且东北部到西南部旱情呈递增趋 势; 生长期西南部为特大干旱, 中部地区为中 


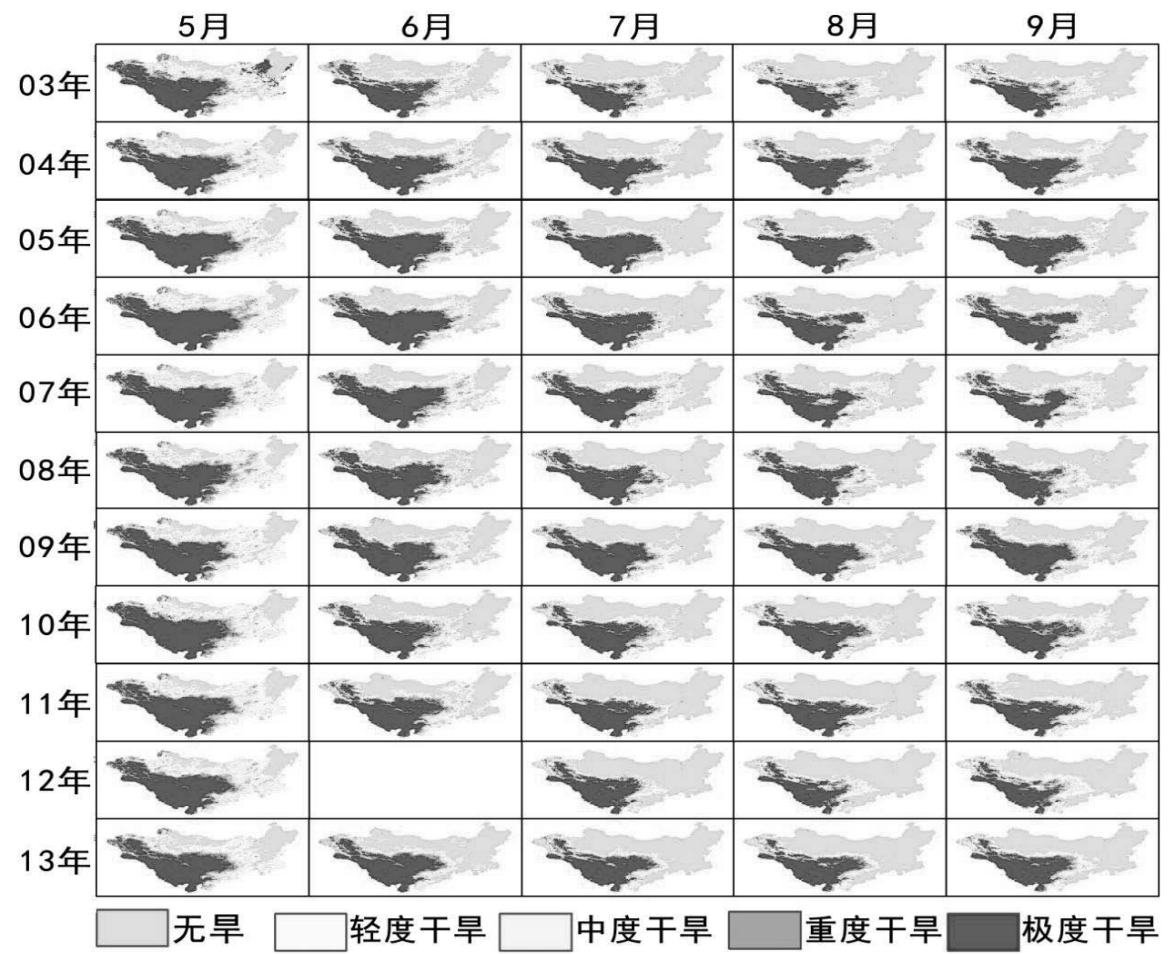

图 5. VSWI 早情监测结果

度干旱为主, 东北部为轻度干旱。5-9 月旱情 减缓趋势，2007 年年旱情最为严重。

在生长季发生最大面积极度干旱的年份 为 2005 年, 干旱面积为 490.95 万平方公里; 重度干旱和无旱面积最大年份都发生在 2003 年生长季, 干旱面积分别为 124.1825 和 661.8575 万平方公里; 中度和轻度干旱最大面 积都发生在 2007 年生长季, 面积分别为 294.2975 和 188.8075 万平方公里。

从 VSWI 空间分布结果发现: 2003-2013 年生长季蒙古高原重度以上干旱主要分布于 高原西部及中部区域, 发生面积占研究时段的 $52.7 \%$ 和 $47.3 \%$ （表 4); 中度干旱在高原的东 部和中部区域, 发生面积均占研究时段的 $14.5 \%$ 。轻度干旱主要分布于高原西部区域, 发生面积占研究时段的 $34.5 \%$ 。

\section{2 与实测数据的拟合情况}

利用 ARCGIS 软件提取实测土壤湿度所 对应的旱情遥感监测指数值, 再运用相关矩阵
法分析各指数与实测土壤湿度数据之间的相

表 4. .03-13 年生长季干早面积占研究时段百分比 (\%)

\begin{tabular}{clll}
\hline 等级 & 东部 & 中部 & 西部 \\
\hline 重度以上 & $1.8 \%$ & $47.3 \%$ & $52.7 \%$ \\
\hline 中度 & $14.5 \%$ & $14.5 \%$ & $7.3 \%$ \\
\hline 轻度 & $3.6 \%$ & $5.5 \%$ & $34.5 \%$ \\
\hline 无早 & $81.8 \%$ & $32.7 \%$ & $5.5 \%$ \\
\hline 注: 重度以上包括重度和极度两个等级。
\end{tabular}

关性。从表 5 可以看出研究区 2004-2012 年的 $5-9$ 月的 $\mathrm{VCI}$ 与 $\mathrm{TCI} 、 \mathrm{VHI}, \mathrm{VSWI}$ 与 $10 \mathrm{~cm}$ 土 壤相对湿度的相关系数。

从表 5 可以看出除了 $\mathrm{VCI}$ 指数的 9 月份 的拟合结果, VCI、TCI、VHI, VSWI 四个 指数与 $10 \mathrm{~cm}$ 土壤相对湿度的相关系数均以通 过了 0.01 的显著性检验。其中, VCI 与 $10 \mathrm{~cm}$ 土壤相对湿度的相关系数在 7 月份的 $10 \mathrm{~cm}$ 土 壤相对湿度存在中度显著相关; 而且 $\mathrm{TCI}$ 与 $10 \mathrm{~cm}$ 土壤相对湿度的相关系数在 7 月份的 $10 \mathrm{~cm}$ 土壤相对湿度存在中度显著相关; VHI 
Risk Analysis and Crisis Response in Big Data Era (RAC-16)

\begin{tabular}{|c|c|c|c|c|c|}
\hline \multirow{2}{*}{ 指数 } & \multicolumn{5}{|c|}{$10 \mathrm{~cm}$ 土壤相对湿度 } \\
\hline & 5 月(样本数) & 6 月(样本) & 7 月(样本) & 8 月(样本) & 9 月(样本) \\
\hline TCI & $0.176 * *$ & $0.181 * *$ & $0.342 * *$ & $0.280 * *$ & $0.174 * *$ \\
\hline VCI & $0.19 * *$ & $0.232 * *$ & $0.329 * *$ & $0.247 * *$ & 0.091 \\
\hline VHI & $0.269 * *$ & $0.335 * *$ & $0.398 * *$ & $0.304 * *$ & $0.166^{* *}$ \\
\hline VSWI & $-0.313^{* *}$ & $-0.359 * *$ & $-0.455^{* *}$ & $-0.203 * *$ & $-0.109 *$ \\
\hline
\end{tabular}

注: $* *$ 相关性高度显著, *显著相关。

与 $10 \mathrm{~cm}$ 土壤相对湿度的相关系数在 $6 、 7 、 8$ 月份的 $10 \mathrm{~cm}$ 土壤相对湿度存在中度显著相关; VSWI 与 $10 \mathrm{~cm}$ 土壤相对湿度的相关系数在 5 、 $6 、 7$ 月份的 $10 \mathrm{~cm}$ 土壤相对湿度存在中度显著 相关。可以发现 VHI 与 VSWI 两个指数在时 空上都有较好的较稳定。

\section{4. 结论与讨论}

(1)条件植被指数（VCI）适合长时间的区域尺 度的宏观相对干旱动态监测, 是个有效和简单 实用的干旱监测方法。但是, 需要长期的历史 遥感数据, 而且, 由于蒙古高原地区植被覆盖 较低, 因此, 除了植被长势最好的 7 月以外的 其他月份植被指数的条件 $(\mathrm{VCI})$ 与实测土壤相 对湿度的拟合效果都是不是特别理想。

(2)温度条件指数 (TCI) 资料容易获得, 且计算 起来简单方便, 适用于监测年度间区域空间尺 度的干旱。但是无法克服由于季节性地温差异 造成的误差。因此，在进行不同月份间的对比 是不适用。

(3)植被受到干旱影响时冠层温度会升高, 同时 植被指数值将会减小, 结合植被冠层温度和植 被指数进行干旱监测能够提高监测的精度。植 被的健康指数 $(\mathrm{VHI})$ 和植被供水指数(VSWI)既 考虑了植被指数的情况, 同时, 还考虑了冠层 温度的情况, 集成了植被条件指数 ( VCI) 和 温度条件指数 $(\mathrm{TCI})$ 的优点。从与实测土壤 相对湿度的结果可以知道, 植被的健康指数 (VHI)和植被供水指数(VSWI)较适用于蒙古高 原的干旱监测。

\section{Acknowledgements}

This study was supported by National Natural Science Foundation of China (No. 41461102), and Science and technology plan projects in
Inner Mongolia multi-scale Mongolia plateau grassland fire risk comprehensive evaluation technology research based on $3 S$, Innovation team of disaster prevention and mitigation of grassland non biological disasters in Chinese Academy of Agricultural Sciences

(CAAS-ASTIP-IGR 2016-0406) and Arxan forest disasters monitoring and early warning and emergency management system research.

\section{致谢}

本研究得到了国家自然基金项目 “基于 $3 \mathrm{~S}$ 技 术的草原火灾风险评估研究一以乌珠穆沁草 原为例” (41461102)、内蒙古科技计划项目 “基于 $3 \mathrm{~S}$ 技术的蒙古高原多尺度草原火灾风 险综合评价技术研究”、中国农业科学院草原 非生物灾害防灾减灾创新团队项目

（CAAS-ASTIP-IGR 2016-0406）、“阿尔山 森林灾害监测预警与应急管理系统研究” 共同 资助。

\section{参考文献}

[1] 王菱,甄霖,刘雪林等.蒙古高原中部气候变 化及影响因素比较研究. 地理研究,2008, 27(1):171-180.

[2] 郭维栋,马柱国,姚永红. 近 50 年中国北方 土壤湿度的区域演变特征.地理学报, 2003, 58:83-90.

[3] 靳英华,廉士欢,周道玮等. 全球气候变化下 的半干旱区相对湿度变化研究.东北师大 学报,2009,41(4):134-138.

[4] 间娜娜. 基于遥感指数的早情监测方法研 究.北京市:中国科学院研究生院,2005.

[5] 郭云开, 张源, 张文博. 植被健康指数及 高等级公路路域环境评价研究. 遥感技术 与应用,2013,28(6):1120-1124.

[6] 曹广真,侯鹏,范锦龙等.TM 与 MODIS 植被 供水指数反演及对比分析. 遥感技术与应 
Risk Analysis and Crisis Response in Big Data Era (RAC-16)

用,2010,25(1):63-68.

[7] Rongfang Li, Lijun Cheng, Yongsheng Ding, Khorasani K, Yunxiang Chen, Wei Wang. An operational drought risk management framework based on stream-flow intelligent internet control. Journal of Risk Analysis and Crisis Response, 2013, 3(1):34-43. 